\title{
Otsin: Sharing the spirit-Development of an indigenous rural nursing practice course
}

\author{
Sheila Blackstock*1,2 \\ ${ }^{1}$ University of Alberta, Edmonton, Alberta, Canada \\ ${ }^{2}$ Thompson Rivers University, Kamloops, British Columbia, Canada
}

Received: June 20, 2018

DOI: $10.5430 /$ jnep.v8n12p29
Accepted: July 8, 2018

URL: https://doi.org/10.5430/jnep.v8n12p29

\begin{abstract}
Otsin is the spirt of Gitxsan Peoples and is reflected by the Gitxsan author sharing the journey in the development of a unique third year undergraduate nursing practice course. The nursing practice course immerses students in a combined rural and an interdisciplinary indigenous nursing practice. The practice course is based on a student centered, context-based teaching pedagogy using a two-eyed seeing approach. The theoretical tenet of place is reconceptualized to reflect Indigenous communities and rural nursing practice. The metaphor of weaving together cedar strips is used to reflect a journey that takes students through the experiences of living and practicing in a rural northern community while embracing on the land experiences, cultural practices, traditions, language and ceremonies. The traditional academy curricula are challenged to broaden the lens beyond the classroom theatre walls to rural, indigenous nursing practice experiences. The weaving of the cedar strips together and allows students to construct their understanding of the impacts of colonization on Indigenous Peoples and an opportunity to be guided by the community to practice cultural safety.
\end{abstract}

Key Words: Indigenous, Rural nursing practice, Curriculum, Student-centered, Two-eyed seeing approach

\section{INTRODUCTION: OTSIN, INTERWEAVING OF CEDAR STRIPS}

The development of a rural, Indigenous health nursing practice course was timely in response to the Truth and Reconciliation Calls to Action ${ }^{[1]}$ and an opportunity to weave interdisciplinary tenets of western nursing ontologies and epistemologies with Indigenous ways of knowing and being into a shared tapestry to insure future sustainability of health services. The metaphor of interweaving of cedar strips is used to represent the interlacing of rural practice, Indigenous nursing, northerner ways, cultural safety, and community. The process of the students weaving the strips will be a personal journey of constructing an understanding of Indigenous ways of being, traditions, language, culture, ceremonies led by Gitxsan Peoples. Otsin means spirit in time immemorial and is shared with nursing students as a foundation to constructing their understanding of cultural safety in nursing practice.

The author reflects on the journey of developing the course as the first cohort of nursing students are about to take the practice course. This shared reflection presents an opportunity to immerse readers, nursing students, and academics in the journey of becoming safely grounded through the two-eyed seeing approach. ${ }^{[2,3]}$ Nursing students enrolled in the course will live and practice in a rural Indigenous community working alongside interdisciplinary teams and Elders to learn from each other with a common goal of recruiting future nurses

*Correspondence: Sheila Blackstock; Email: sblackst@ualberta.ca; Address: University of Alberta, Edmonton, Alberta, Canada. 
and enhancing cultural competence in rural nursing practice, posing the question "Why isn't a requisite rural, Indigenous practice course a part of Schools of Nursing curriculums?' Development of immersion practice encourages us to reflect, question curriculum development, and represents an opportunity to authentically respond to Truth and Reconciliation Calls to Action ${ }^{[1]}$ through the author's journey home.

The course was developed with ends-in view and learning outcomes to give students an opportunity to construct new knowledge and practice cultural safety situated within nursing practice contexts of northern, rural, and Indigenous nursing with the Gitxsan Peoples. The purpose of this paper is to outline the development of a six-week undergraduate rural, indigenous nursing practice course for students completing their third year of studies of an undergraduate program. Students experience a preceptorship experience for three weeks in acute care interdisciplinary practice and three weeks in community health center on reserve (i.e., in community) working with an interdisciplinary team and paraprofessionals.

Creating a rural, indigenous practice experience was an opportunity to respond to the Truth and Reconciliation Calls to Action $^{[1]}$ and has secondary impacts on nursing recruitment and retention. Honoring protocols, engagement of Indigenous Peoples through lessons learnt in northern, rural roots, partnerships and embracing a student-centered teaching pedagogy prompts a shift in the academic lens. ${ }^{[4]}$ Indigenous community members were consulted to clarify protocols and plan community cultural experiences. Honoring protocols and engagement means taking time, building partnerships in defining Indigenous health to shape nursing education. Engagement in the context of developing a nursing practice course was an opportunity to use a different lens or perspective which prompted some reflections. Reflections on being guided by the academic process to create a course and advocating for enough time and place to honor protocols.

\section{Problem statement}

In Canada, the number of Registered Nurses (RN) practicing in rural nursing is declining at an astonishing rate ${ }^{[5]}$ which is compounded by RNs leaving the profession due to an aging workforce. ${ }^{[6]}$ New graduate nurses meant to replace retiring RNs are also leaving the profession. Researcher have determined that $18 \%-30 \%$ of new graduates will leave their current position for a different practice environment or the profession all together in the first year and up to 37\%-57\% will leave in their second year of practice. ${ }^{[7,8]}$ Although, in some cases new graduate nurses are orientated to rural nursing practice, attrition rates remain a problem. ${ }^{[9]}$ It is clear that curricula innovations are needed to provide nursing stu- dents with opportunities to practice in rural nursing practice to support employment in rural acute care environments as new graduate nurses. ${ }^{[10]}$

Development of a nursing practice immersion course for Thompson Rivers University (TRU) is timely given the Truth and Reconciliation Commission of Canada's Calls to Action. ${ }^{[1]}$ The Truth and Reconciliation Calls to Action ${ }^{[1]}$ echo in the valley walls at the confluence of the Skeena and Bulkley Rivers with the hope of positively impacting health outcomes of Indigenous peoples. Further, a focus on rural nursing practice has secondary benefits of immersing students in a northern, rural nursing practice environment context. When nursing students experience rural health nursing practice within an interdisciplinary team their competence to practice in rural contexts as new graduates improves leading to higher rates of retention and positive health outcomes of rural communities. ${ }^{[9]}$

\section{BACKGROUND}

\subsection{Place: Rural \& indigenous nursing practice}

What if the academic lens and the theoretical tenet of place was expanded to include rurality and Indigenous nursing practice? The exploration of place and protocol is shared to offer insights to academics pursuing Indigenous course development. The notion of place has historical underpinnings to Nightingale's work in the evolution of the nursing profession $^{[11]}$ that has been translated to unique constituted meanings. Place has been conceptualized as having three distinct but interrelated components: location, situatedness, locus $^{[12]}$ that has relevance and meaning for the provision of nursing care to individuals, family, and communities. Place and the importance of change of place, can be interpreted as conceptualizations of tenants of the client, health care, practice environment, and rural community. When students experience conceptualizations of place (i.e. in the context of rural and indigenous practice) they reflect, interpret, and translate what they learn into a new conceptualization of rural indigenous nursing practice. The student's conceptualizations can take on a life of its own, being a place in and of itself in an intrinsically lived experience.

Place immersed within a nursing curriculum is the embodiment of knowing (empirical, ethical, aesthetical, persona, unknowing, sociopolitical, and emancipatory) in situated cognition. ${ }^{[11]}$ Utilizing storytelling as a format of translating place is a traditional pedagogical method practiced by Indigenous Peoples has meaning and relevance to nursing curriculum, research and practice. A story of place can capture the pedagogical underpinnings of nursing akin to the carved Gitxsan totem poles representing the knowledge, oral 
history and languages restored, and disseminated through stories shared by elders. The land surrounding the totem is representative of the knowledge from our Elders and optimal well-being of individual, family, and community. In the context of nursing, the land is fertile soil, nurturing knowledge and translating Indigenous ways of knowing concurrently through Indigenous nursing education and practice. The wooden pole, carved animal spirits, accentuated by colors and environment surrounding the totem culminate to represent the embodiment of knowing and not knowing; situated cognition emancipated through nursing domains representative of holistic nursing education translated to holistic nursing care. The paradigm of place has meaning to impart foundational nursing knowledge that provides a holistic, meaningful foundation for the provision of culturally sensitive health care to communities reflective of culturally respectful and holistic nursing research informing nursing practice and ultimately the wellbeing of individuals, families and communities.

Inclusion of place offers promise to naturally embed decolonizing process and inherently ensure the honoring of protocols if academics shift their academic lens- insuring protocols and community engagement are honored. ${ }^{[4]}$ Place is not merely a subset of the social determinant of health, rather it is geographical material and ecological entity; earth, water, land ${ }^{[13]}$ and situates ceremony, and traditions. Place extends to oral history and the creation of new historical, political influences that impact health and health outcomes. Moving from student-centered approaches in the classroom that can silo students to being situated within community, requires engagement and partnerships with the community from the outset. ${ }^{[14]}$ This approach has relevance to the integration of Indigenous knowledge and by extension the inclusion of protocols, culture and relationships using place. Recently, compelling evidence shows that culturally restorative practice frameworks ${ }^{[15]}$ inherently integrates tenets of place and shows promise to facilitate relationships amongst societies and cultures that have endured colonization and oppression. Similarly, decolonizing frameworks that utilize equity and social justice lens are integral to educating academics on Indigenous knowledge to avoid tokenism and essentialism integration into curriculum as an eager reaction to Truth and Reconciliation Calls to Action. ${ }^{[1]}$

\subsection{Decolonization of nursing: Building capacity of nurses}

Nurse educators can redress a decolonizing framework utilizing a relational accountability. This approach challenges the status quo of following the Eurocentric influences of teaching health promotion frameworks, policy influences, and developing nursing curriculum. Relational practice approaches

Published by Sciedu Press embrace reflective interactions using three lenses examining: self, interpersonal relationships and health systems ${ }^{[16]}$ that can build capacity of non-Indigenous academics to engage with Indigenous communities. Critically challenging the status quo ${ }^{[17]}$ insures that nursing curriculum developers engage Indigenous ways of knowing and challenging historical influences, marginalizing power, policy, and structural determinants of health that sustain colonizing perspectives. ${ }^{[18,19]}$ Curriculum developers can rewrite health history by using a decolonization approach in nursing curriculum and course content. Decolonization of nursing is a step forward to ensure that nursing graduates have the capacity to be reflexive in nursing practice and the potential to increase retention of nursing graduates in Indigenous communities.

Evidence demonstrates there are several factors that nursing educators can 'reshape' to influence and advance nursing students' experiences and education ${ }^{[20]}$ that ultimately impact retention and recruitment in Indigenous communities. In particular, integration of interdisciplinary approaches that require collaboration and understanding of respective roles in health care teams within Indigenous health care settings have been suggested as a priority approach to improve retention of nursing graduates. When nursing students are not given the opportunity to learn how to practice cultural safety and to work within interdisciplinary teams in a collaborative manner it becomes a barrier to actualizing optimal Indigenous health outcomes. ${ }^{[21]}$ Further, when nursing students do not receive support to enact Intercollaborative practice (i.e., mix of para, health, social, non-professionals) when governed by administrators in Indigenous health care organizations off reserve or on reserve, their scope of nursing practice becomes constrained within the healthcare setting and may lead to dissatisfaction and ultimately nurses leaving indigenous nursing practice areas where it is needed most. Schools of nursing have an opportunity to have curricula informed by intercollaborative, cultural safety, and postcolonial frameworks to situate and build capacity of nursing faculty to improve nursing education. Secondary impacts on recruitment and retention of nurses working in partnership with Indigenous communities in curriculum development and research to positively impact health outcomes. Further, the advancement of academic structures to allow time to build partnerships with Indigenous Peoples to enact and follow protocols allows for an authentic, respectful engagement of Indigenous Peoples with Schools of Nursing.

\subsection{Rural nursing}

Rural, remote northern landscapes are woven by a tapestry of fresh, glacial water tributaries cresting glacial divides, snow crested rugged mountains, flora, fauna, and an abundance 
of wildlife. Rural communities are often 'unincorporated' having minimal services and a handful of stores and a gas station for essentials. People living in rural, remote northern communities develop a form of citizenry that is based on a strong moral conscience, responsibility, a sense of reciprocity of caring, solution focused, and most importantly humility; these factors combined are part of a northerner's constitution or ways of being.

Research findings have echoed the northern mentality and sentiments as it relates to preparing new graduate nurses to take on rural nursing that the key is not to fix problems, but rather work together in partnership with individuals and community to problem solve. ${ }^{[22]}$ Nurses working within an interdisciplinary team in rural hospitals this sense of 'being a northerner' is echoed in the relationships amongst team members having to do what is necessary often with a scarcity of resources both physical, and human resources to care for patients brought in by ambulance or walking through the emergency doors. Nursing experience is gained through the expertise of your colleagues and through working as a team in rural practice. Although benefits of sharing experiences are pedagogically sound in teaching nursing, providing nursing students practice experiences bridges theory to practice gaps, and provides an opportunity to experience northern, rural nursing.

\subsection{Gitxsan nursing: Constructing cultural safety}

As nursing academics, it can be challenging to discern whether students understand the significance of northern sense of reciprocity, teamwork and rurality as it relates to Indigenous nursing practice. Further, as the Truth and Reconciliation Calls to Action ${ }^{[1]}$ are being responded to within the academy developing a rural, nursing Indigenous practice course provides students with an opportunity to practice cultural safety. Students are provided the honour of being on the land with Indigenous Peoples, guided by knowledge keepers and Elders. Gitxsan Peoples are rich in a holistic cultural approach inclusive of ceremony, language, land, a charismatic sense of humour, and embody the meaning of welcoming and northerner ways of being all at once. This culmination of holistic approach guides nursing students to experience the culture, language and the effects of self-determination to construct, apply, and practice cultural safety.

\section{LiterATURE REVIEW}

\subsection{Rural nursing practice experience situation and op- portunity}

The notion of a scarcity of resources (including human, technical, supplies and time) is amplified within the practice context of rural nursing. Rural nursing practice are affected by even small fluctuations in staff turnover. ${ }^{[23]}$ Registered Nurses are situated within the matrix of health care funding shortfalls, declining professional practice support and professional development. New graduates can fill nursing positions for a rural health setting, however the scarcity of seasoned nurses presents a challenge to mentoring new nurses. Seasoned nurses feel stretched from being overworked and yet are passionate about mentoring new graduate nurses to offset the nursing shortages. ${ }^{[24]}$ Although work has been done to explore support for rural and remote new graduate nurses amidst the challenges, there is a paucity of nursing practice experiences prior to graduation. ${ }^{[25]}$ Researchers have recommended that an important factor to ameliorate new graduate nurse recruitment and retention is the formation of strategic partnerships with key stakeholders such as schools of nursing and aboriginal communities. ${ }^{[26]}$ An opportunity is proposed for nursing schools to offer undergraduate students rural and Indigenous health practice experiences that push the boundaries of traditional curricula and allow for experiential learning in rural, indigenous, and collaborative practice contexts.

\subsection{Collaborative practice with paraprofessionals and professionals within an interdisciplinary team}

The issues associated with a decline in new graduate nurses working in rural practice is compounded within Indigenous health care practice. The complexities of governance as communities' transition to self-determination in health through health transfer, self-government agreements, and community development is often an unknown entity to newly employed registered nurses and graduate nurses working in Indigenous communities. Having a non-nursing governance of a health care agency that may be comprised of band members means that the registered nurses must be self-directed and be able to plan, develop and partner with other agencies all within their scope of practice. This can be overwhelming for new employees despite years of nursing experience as well as new graduate nurses. In addition, the interdisciplinary team compliment is often comprised of para professionals, elders, medicine people, and other professionals. A review of factors contributing to retention and attrition of indigenous nurses working in Indigenous communities noted, among other factors, that understanding the interprofessional linkages can strengthen support for Indigenous nurses. ${ }^{[27]}$ New graduate nurses have had few opportunities to experience a staff mix similar to Indigenous interprofessional teams.

\subsection{Practicing cultural safety}

In the past decades, researchers, health authorities and educators have focused on facilitating cultural understanding

ISSN 1925-4040 E-ISSN 1925-4059 
to address health inequities between Indigenous and nonindigenous people in BC and Canada. ${ }^{[28,29]}$ Cultural safety is used to improve health care delivery to Indigenous Peoples in BC and across the nation to address health inequities. Cultural safety extends beyond cultural competency in nursing practice through understanding inherent power differentials in health service delivery and redressing inequities. ${ }^{[30]} \mathrm{Re}-$ cently, researchers made the following recommendations in curricula development and program implementation: redesign programs; lobby for mandatory and thoroughly integrated cultural safety education; and continue to model, evaluate and provide constructive feedback to students and practicing professionals. ${ }^{[31]}$ Student nurse feedback suggests that they need a safe environment to actually practice cultural safety and are advocating for teaching modalities that integrate theory and practice which echoed in the literature by health students. ${ }^{[32]}$

\section{NuRsing PRACTICE COURSE DEVELOP- MENT}

\subsection{Practice education framework and theories}

Indigenous community and land based cultural experiences culminate to strengthen the capacity and sustainability of the practice course. Further as mentioned earlier, a two-eyed seeing approach was used to inform the course design. A shared approach to recognize and integrate respective epistemologies and ontologies of western and Indigenous ways of knowing and being. Methodologies that incorporate evidenced based approaches and community involvement and participation echoes the intent of a two-eyed seeing approach. ${ }^{[2,3]}$ "Learning to see from one eye with the strengths of (or best in) Indigenous knowledge and ways of knowing and learning to see from the other eye with the strengths of (or best in) Western knowledge and ways of knowing and most importantly, using both eyes together for the benefit of all."[3]

The Aboriginal Practice Education Framework ${ }^{[33]}$ was used to guide the course development to evaluate and determine the sustainability and community capacity. The evaluation demonstrated a mastery competency for students reflecting an increasing degree of intentionality in supporting students in practice education. Practice education that has learning outcomes of application, modelling reflexivity, and coconstruction of nursing priorities with Indigenous communities. Students experience working with an interdisciplinary, paraprofessional team both in the context of a rural hospital and with an Indigenous health agency that has six on reservice health clinics that have received accreditation with commendation from Accreditation Canada ${ }^{[34]}$ in 2016.

Published by Sciedu Press

\subsection{Pedagogy, indigenous philosophies, and community partnerships}

Interweaving Indigenous philosophies, cultural safety and community partnerships offers a new pedagogy of teaching nursing practice. A nursing immersion practice course allows the nursing curricula lens to extend beyond the classroom theatre walls and embraces a student-centered teaching philosophy. When students are immersed in nursing practice within Indigenous communities they experience Indigenous philosophies, ways of knowing grounded in ceremony, practice cultural safety, and learn the language with community health care team members.

Indigenous philosophies consider life sacred and rooted to the [mother] earth. ${ }^{[35]}$ This is a different way of knowing and living than is practised by Western society and calls for an ecosophy-a harmony between the ecosystem and philosophy. ${ }^{[36]}$ Indigenous philosophy is grounded in spirituality, ceremony and language is central in aboriginal epistemology. It was important for the community to share their oral history with the students through having students experience on the land cultural traditions such as: poplar bud gathering and making healing salves; gathering cedar strips to weave traditional regalia; and making button blankets. The students will be invited to attend cultural gatherings such as honoring the salmon, nature walks with elders, salmon feast, smoke feast, and potlatch.

Aboriginal epistemology is the essence of complimentary modes of knowing, shared, and transmitted through the historical oral tradition. ${ }^{[37]}$ When oral history called adaawk in Gitxsan, is not shared in language, ceremonial practices, song and prayer, ancestral history and knowledge is lost. Students are supported to experience personal oral experiences of translation of knowledge and sharing by participating in weekly sharing circles with the instructor to unpack their experiences in practice and to create oral reflective journaling to articulate how they are meeting goals and quality nursing practice indicators.

\subsection{Student learning context}

The term Indigenous community is understood to include a rural hospital and on six on reserve health clinics and community hospital and diagnostic and treatment centers. Students develop their abilities to engage in more complex assessment and decision-making in a variety of practice settings. They will increase their understanding of the role of a nurse within an interdisciplinary team of professionals and paraprofessionals. In addition, students have an opportunity to apply their evolving understanding of the discipline of nursing and nursing inquiry. Learners will work with moderate levels of client and contextual complexity and require moderate levels 
of supervision.

\subsection{Learning outcomes}

Students will have an opportunity to understand how worldviews impact holistic health to understand to facilitate nursing and relational inquiry with individuals, families and communities. They will be guided in model reflexivity in nursing practice with individuals, families and communities will demonstrate their understanding through sharing circles and oral journaling. During the practice course, students will understand how nursing practice, supported by a decolonizing approach facilitates positive health outcomes for Indigenous Peoples. They will co-create innovative approaches through working collaboratively with team members and peers to evaluate and apply theoretical concepts of relational practice. The students will be challenged to co-create nursing priorities, goals with individuals, families and communities to positively impact health outcomes. This is a unique opportunity for student to appraise nursing priorities, goals within the nursing practice environment and articulate within a paraprofessional and professional interdisciplinary team. Finally, students will remember Indigenous ways of knowing and being to facilitate engagement and partnerships with Indigenous Peoples in nursing practice, community development and research.

\subsection{Evaluation}

Evaluation will occur by key participants, the students, health care institutions, community, and the instructor. The students will be given evaluations for each practice area to evaluate the instructor as well as the university generated course evaluations at the end of the practicum. The author will meet with each agency involved in the practicum to get feedback on their preceptorship experience and having students in the agency.

\section{Conclusion: Gathering CEDAR STRIPS...PREPARING TO WEAVE}

A key aspect of cedar strip gathering for weaving is that this a traditional practice originating from coastal tribes and brought to the Gitxsan territories to create head dresses and head bands for traditional regalia and for baskets for gathering of berries, fish and medicines. The cedar strips woven together bring strength for heavy loads and are often made into twine for rope. Elders say the first step in cedar gathering is to honor the cedar tree through a song, or an offering. Cedar strips are harvested only from trees that are mature enough that one strip will not inadvertently harm the tree. Cedar strip gatherers go out in groups with Elders, knowledge keepers and youth to share the tradition. It is important that the strips are cleaned in the bush and during this time songs are sung, and there is a feast while everyone works together. The students will learn to weave using five strips of cedar for a headband to wear at their convocation. Each one of the cedar strips will represent a part of their experience in their course, rural northern practice, Gitxsan People, their journey, and relational cultural safety interactions with community members they will work with and meet. The woven cedar headband will be one reminder of the Otsin, the spirit of Gitxsan Peoples. When the cedar strips have been woven culminating at the end of the first nursing practice the outcome of this journey will be shared once again.

\section{ACKNOWLEDGEMENTS}

Respectfully acknowledge the Gitxsan Peoples, and Star Mahara, Associate Professor Thompson Rivers University.

\section{CONFLICTS OF INTEREST Disclosure}

The author declares there is no conflict of interests.

\section{REFERENCES}

[1] Truth and Reconciliation Commission of Canada [TRC] 2015. Calls to action. Winnipeg, MB: TRC. Available from: http://www.trc.ca/websites/trcinsitution/File/2015/ Findings/Exec_Summary_2015_05_31_web_e.pdf

[2] Marshall M, Marshall A, Bartlett C. Two-eye seeing in medicine: In Greenwood, M., De Leeuw, S., Lindsay, N.M., \& Reading, C. (Eds). Determinants of Indigenous People's Health in Canada: Beyond the Social. Toronto, ON: Canada Scholar's Press; 2015. 17 p.

[3] Bartlett C, Marshall M, Marshall A, et al. Integrative science and two-eyed seeing: Enriching the discussion framework for healthy communities. In Hallstrom, L.K., \& Guehlstorf, N.P., \& Parkes, M.W. (Eds). Ecosystems, Society and Health: Pathways through diversity, convergence, and integration. McGill-Queens University, Montreal: AU. 2015. 280-236 p.
[4] Blackstock SY. Shifting the academic lens: Development of an interdisciplinary health nursing course. Journal of Nursing Education and Practice. 2017; 7(1).

[5] Baumann A, Hunsberger M, Blythe J, et al. The new healthcare worker: The implications of changing employment patterns in rural and community hospitals. Health Human Resource Series (6). Ontario: McMaster University. 2006.

[6] Canadian Institute of Health Information. Regulated nurses, 2015. Available from: https://secure.cihi.ca/free_products/N ursing_Report_2015_en.pdf

[7] Laschinger HKS, Grau AL, Finegan J, et al. Predictors of new graduate nurses' workplace wellbeing: Testing the job demands-resources model. Health Care Management Review. 2012; 37(2): 175-186. PMid:21799432 https://doi.org/10.1097/HMR. Ob013e3182 2 aa456 
[8] Chandler GE. Succeeding in the first year of practice: Heed the wisdom of novice nurses. Journal for Nurses in Staff Development. 2012; 28(3): 103-107. PMid:22617780 https ://doi .org/10.1097/NN D. 0 b013e31825514ee

[9] First Nations Health Authority: Health through wellness: Nursing Review. 2015. Available from: http///www. fnha.ca/what-we-d -o/nursing-services

[10] Smith JC, Vandall-Walker V. A double whammy! New baccalaureate registered nurses' transition into rural acute care. Rural and Remote Health. 2017; 17: 4256. PMid:29284273

[11] Thomas EA. Restoring the place work of nursing. Journal of Holistic Nursing. 2013; 31(4): 267-275. PMid:24045704 https://doi .or $\mathrm{g} / 10.1177 / 0898010113501019$

[12] Carolan M, Andrews GJ, Hodnett E. Writing place: a comparison of nursing research and health geography. Nursing Inquiry. 2006; 13(3): 203-219. PMid:16918788 https://doi org/10.1111/j. 1440-1800.2006.00322.x

[13] De Leeuw S. Activating Place: Geography as a determinant of Indigenous Peoples health and well-being. In Greenwood, M., De Leeuw, S., Lindsay, M.M, \& Reading, C. (Eds), Determinants of Indigenous Peoples' Health in Canada: Beyond the Social. Toronto: Canadian Scholar's Press; 2015.

[14] Stansfield D, Browne A. The Relevance of Indigenous knowledge for nursing curriculum. International Journal of Nursing Education Scholarship. 2013; 10(1): 1-9.

[15] Simard E. Culturally restorative child welfare practice-a special emphasis on cultural attachment theory. First Peoples Child Family Review. 2009; 4(2): 44-61.

[16] Rix EF, Barclay L, Wilson S. Can a white nurse get it? 'Reflexive practice' and the non-Indigenous clinician/researcher working with Aboriginal people. Rural and Remote Health. 2012; 14: 2679.

[17] Lavoie JM, Forget E, Browne AJ. Caught at the crossroad: First Nations, health care and the legacy of the Indian Act. Pimatisiwin: A Journal of Indigenous and Aboriginal Community Health. 2010; 8(1): 83-100.

[18] McGibbon E, Mulaudzi FM, Didham P, et al. Toward decolonizing nursing: the colonization of nursing and strategies to create the counter-narrative. Nursing Inquiry. 2014; 21(3): 179-191. PMid:23837570 https://doi.org/10.1111/nin.12042

[19] Sherwood J, Edwards T. Decolonisation: A critical step for improving Aboriginal health. Contemporary Nurse. 2006; 22(2): 178-190. https://doi.org/10.5172/conu.2006.22.2.178

[20] Martin D, Kipling A. Factors shaping aboriginal nursing students' experiences. Nurse Education in Practice. 2006; 6(6): 380-288. PMid:19040905 https://doi.org/10.1016/j.nepr.2006.07 .009

[21] Purden M. Cultural considerations in interprofessional education and practice. Journal of Interprofessional Care. 2005; S1: 224-234.

[22] Misener RM, MacLeod MLP, Banks K, et al. There's rural, and then there's rural: Advice from nurses providing primary healthcare in northern remote communities. Journal of Nursing Research. 2008; 21(3): 55-63.

[23] Rheaume A, Clement L, LeBel N. Understanding intention to leave amongst new graduate Canadian nurses: a repeated cross-sectional survey. International Journal of Nursing Studies. 2011; 48(4): 490-
500. PMid:20863497 https://doi.org/10.1016/j.ijnurstu .2010 .08 .005

[24] Rush K, Adamack M, Gordon J, et al. Best practices of formal new graduate nurse transition programs: An integrative review. International Journal of Nursing Studies. 2012; 50(3): 345-356 PMid:22795800 https://doi.org/10.1016/j.ijnurstu. 201 2.06.009

[25] Rudman A, Gustavsson JP. Early career burnout among new graduate nurses: a prospective observational study of intra-individual change trajectories. International Journal of Nursing Studies. 2012; 48(3): 292-306.

[26] Gregory D. Against the odds: An update on aboriginal nursing in Canada. Lethbridge: School of Health Sciences, University of Lethbridge. 2007.

[27] Stewart NJ, Kulig JC, Penz K, et al. Aboriginal nurses in rural and remote Canada: Results from a national survey. Saskatoon College of Nursing Publication; 2006.

[28] Canadian Institutes of Health Research. Natural Sciences and Engineering Research Council of Canada, and Social Sciences and Humanities Research Council of Canada. Research involving the First Nations, Inuit and Metis People of Canada. In Tri-Council policy statement: Ethical conduct for research involving humans. 2nd ed. Available from: http://www.pre.ethics.gc.ca/eng/pol icy-politique/initiatives/tcps2-eptc2/chapter9

[29] Health Canada. Closing the gaps in Aboriginal health. Health Policy Research Bulletin. 2003; 5: 1-41. Available from: http: //www.hc-sc.gc.ca/sr-sr/pubs/hpr-rpms/bull/2003\T1 textendash5-aboriginal-autochtone/index-eng.php

[30] ANAC. Cultural competence and cultural safety in nursing education. A framework for first nations, inuit and metis nursing.2009. Available from: https://www.cna-aiic.ca/ /media/cna/page-conte nt/pdf-en/first_nations_framework_e.pdf

[31] Guerra O, Kurtz D. Building collaboration: A scoping review of cultural competency and safety education and training for health care students and professionals in Canada. Teaching and Learning in Medicine: An International Journal. 2017; 29(2): 129142. PMid:27813660 https://doi.org/10.1080/10401334.2 016.1234960

[32] Alekejuniene J, Zed C, Marino R. Self-perceptions of cultural competence among dental students and recent graduates. Journal of Dental Education. 2014; 78: 389-400. PMid:24609341

[33] Aboriginal Nurses Association of Canada/Canadian Association of Schools of Nursing/Canadian Nurses Association. Cultural Competence and Cultural Safety in Nursing Education: A Framework for First Nations, Inuit and Metis Nursing. Ottawa: ANAC. 2009.

[34] Accreditation Canada. Available from: https://accreditation. ca/accreditation/

[35] Cajete G. Native science: Natural laws of interdependence. Clear Light Publishers; 2000.

[36] Campbell TD. A clash of paradigms? Western and indigenous views of health research involving aboriginal peoples. Nursing Research. 2014; 21(6): 39-43. PMid:25059087 https://doi.org/10.774 8/nr.21.6.39.e1253

[37] Battiste M. Enabling the autumn seed: Toward a decolonized approach to aboriginal knowledge, language and education. Canadian Journal of Native Education. 1998. 